\title{
RNA Interference Screen Reveals an Essential Role of Nedd4-2 in Dopamine Transporter Ubiquitination and Endocytosis
}

\author{
Tatiana Sorkina, Manuel Miranda, Kalen R. Dionne, Brian R. Hoover, Nancy R. Zahniser, and Alexander Sorkin \\ Department of Pharmacology, University of Colorado at Denver and Health Sciences Center, Aurora, Colorado 80045
}

The function of the dopamine transporter (DAT) to terminate dopamine neurotransmission is regulated by endocytic trafficking of DAT. To elucidate the mechanisms of DAT endocytosis, we generated a fully functional mutant of the human DAT in which a hemagglutinin epitope (HA) was incorporated into the second extracellular loop. The endocytosis assay, based on the uptake of an HA antibody, was designed to study constitutive- and protein kinase $\mathrm{C}$ (PKC)-dependent internalization of HA-DAT expressed in non-neuronal cells and rat dopaminergic neurons. Large-scale RNA interference analysis of PKC-dependent endocytosis of HA-DAT revealed the essential and specific role of an E3 ubiquitin ligase, Nedd4-2 (neural precursor cell expressed, developmentally downregulated 4-2), as well as the involvement of adaptor proteins present in clathrin-coated pits, such as epsin, Eps15 (epidermal growth factor pathway substrate clone 15), and Eps15R (Eps15-related protein). Depletion of Nedd4-2 resulted in a dramatic reduction of PKC-dependent ubiquitination of DAT. Endogenous Nedd4-2, epsin, and Eps15 were coimmunoprecipitated with heterologously expressed human HA-DAT and endogenous DAT isolated from rat striatum. A new mechanistic model of DAT endocytosis is proposed whereby the PKC-induced ubiquitination of DAT mediated by Nedd4 -2 leads to interaction of DAT with adaptor proteins in coated pits and acceleration of DAT endocytosis.

Key words: dopamine transporter; HA epitope tag; endocytosis; RNA interference; ubiquitination; Nedd4 -2

\section{Introduction}

The dopamine transporter (DAT) is localized to dopaminergic neurons where its primary function is to transport dopamine (DA) from the extracellular milieu into DA neurons, thus terminating DA signaling. Also, cocaine and amphetamines interact with DAT to produce psychomotor stimulation. DAT belongs to a family of $\mathrm{Na}^{+}-\mathrm{Cl}^{-}$coimporters that also includes plasma membrane transporters for norepinephrine, $\gamma$-aminobutyric acid, serotonin, and glycine (Torres et al., 2003; Chen et al., 2004). These transporters contain 12 predicted transmembrane $\alpha$-helices with both $\mathrm{N}$ and $\mathrm{C}$ termini oriented into the cytoplasm. In the predicted structure, all extracellular and intracellular loops are very short, with the exception of the second extracellular loop (EL2) that contains several $N$-glycosylation sites. The predicted topology of this family of transporters is in good agreement with the recent $\mathrm{x}$-ray structure of the homologous bacterial leucine transporter (Yamashita et al., 2005).

Because DAT functions at the plasma membrane, the number of DATs at the cell surface of the neurons determines the duration and spatial limitations of dopaminergic neurotransmission. Dur-

Received March 27, 2006; revised June 29, 2006; accepted June 29, 2006.

This work was supported by National Institutes of Health Grants DA014204, DA019980, and DA015050. We thank Dharmacon, Inc. for generating an siARRAY RTF endocytosis library and Drs. Di Fiore, Staub, Thomas, and Traub for the gifts of reagents. We are grateful to Fangtian Huang and Gaynor A. Larson for help with RTF screening of transferrin endocytosis and preparation of striatal slices, respectively.

Correspondence should be addressed to Alexander Sorkin, Department of Pharmacology, University of Colorado at Denver and Health Sciences Center, Aurora, $C 0$ 80045. E-mail: alexander.sorkin@uchsc.edu.

DOI:10.1523/JNEUROSCI.1301-06.2006

Copyright $\odot 2006$ Society for Neuroscience $\quad$ 0270-6474/06/268195-11\$15.00/0 ing the last decade it was recognized that the surface pool of DAT is dynamic (e.g., DAT can be internalized into endosomes and recycled back to the cell surface) (Melikian, 2004; Zahniser and Sorkin, 2004). Therefore, the relative rates of DAT endocytosis and recycling may determine the size of the functional pool of DATs. The regulatory mechanisms of DAT endocytic trafficking, however, are not understood. In non-neuronal cells, heterologously expressed DAT is constitutively internalized and recycled (Loder and Melikian, 2003; Sorkina et al., 2005). Internalization of DAT can be accelerated by activation of PKC and by DAT substrates (Daniels and Amara, 1999; Melikian and Buckley, 1999; Saunders et al., 2000; Chi and Reith, 2003; Gulley and Zahniser, 2003). Activation of PKC is also proposed to increase lysosomal degradation (Daniels and Amara, 1999; Miranda et al., 2005) and reduce recycling of DAT (Loder and Melikian, 2003).

Both constitutive and PKC-dependent internalization of DAT primarily occur via clathrin-coated pits (Sorkina et al., 2005). Proteins that recruit DAT into clathrin coated pits are not known. DAT lacks conventional internalization signals, although juxtamembrane sequences of the $\mathrm{C}$ terminus have been proposed to be involved in DAT internalization (Holton et al., 2005). We have recently demonstrated PKC-dependent ubiquitination of DAT and proposed that ubiquitin moieties may serve as internalization and/or lysosomal targeting signals (Miranda et al., 2005). In general, the lack of a specific antibody to the extracellular sequences of DAT that can be used as a "ligand" to monitor DAT endocytosis in living cells has hindered the quantitative analysis of the mechanisms by which DAT and other transporters of this family are endocytosed. 
Hence, we generated a fully functional DAT mutant that contains a hemagglutinin (HA) epitope-tag in the EL2. The generation of an extracellular-tagged DAT allowed us to use an "antibody feeding" assay to study DAT endocytosis. Using this assay we performed screening of a library of small interfering RNAs (siRNAs) targeting endocytosis proteins and identified several proteins that are necessary for PKC-induced DAT endocytosis. Among these proteins, the E3 ubiquitin ligase Nedd4-2 (neural precursor cell expressed, developmentally downregulated 4-2) was found to have a specific and essential role in DAT ubiquitination and endocytosis.

\section{Materials and Methods}

Reagents. Antibodies were purchased from the following sources: monoclonal rat antibody against the $\mathrm{N}$ terminus of DAT and rabbit polyclonal antibody to tyrosine hydroxylase (TH) from Chemicon (Temecula, CA); polyclonal goat anti-DAT from Santa Cruz International (Santa Cruz, CA); mouse monoclonal antibody HA11 from Covance (Berkley, CA); donkey anti-mouse antibodies conjugated with cyanine 5 (Cy5) or Cy3 from Jackson ImmunoResearch (West Grove, PA); goat anti-rabbit antibody conjugated with Alexa-350 from Invitrogen (Eugene, OR); sheep anti-mouse ${ }^{125}$ I-conjugated antibody from Amersham Biosciences (Buckinghamshire, UK). Rabbit polyclonal antibody to Nedd4-2 was a kind gift from Dr. Staub (University of Lausanne, Lausanne, Switzerland), rabbit antibody 577 to Eps 15 and 860F to Eps15R were gifts from Dr. P. P. Di Fiore (European Cancer Institute, Milan, Italy), and an antibody to epsin-1 was a gift from Dr. L. Traub (University of Pittsburgh, Pittsburgh, PA). Phorbol 12-myristate 13-acetate (PMA) was purchased from Sigma (St. Louis, MO).

Plasmids. The plasmid yellow fluorescent protein (YFP)-DAT was described previously (Sorkina et al., 2003). To generate YFP- and HAtagged DAT, residues 193-203 of human DAT were replaced in YFPDAT to the sequence of YPYDVPDYASL (HA epitope is underlined) using a Stratagene (La Jolla, CA) Quick-change mutagenesis kit according to the manufacture's protocol. The mutations were verified by automatic dideoxynucleotide sequencing. To generate a full-length DAT that contained an HA tag in the EL2 but was not fused to YFP, a DNA fragment between $\mathrm{Kp} n \mathrm{I}$ and internal ClaI restriction sites in the Flag-HisDAT construct (Miranda et al., 2005) was substituted for the same fragment digested from YFP-HA-DAT. The resulting construct (further referred to as HA-DAT) contained Flag and 10xHis epitope tags at the $\mathrm{N}$ terminus and an HA epitope tag in EL2. The Nedd4-2-GFP (green fluorescent protein) construct was kindly provided by Dr. Thomas (University of Iowa, Iowa City, IA).

Cell culture and transfections. Human HeLa cells were grown in DMEM containing 10\% fetal bovine serum (FBS; HyClone, Logan, UT) and antibiotics. Porcine aortic endothelial (PAE) cells were grown in Ham's F12 medium containing 10\% FBS and antibiotics.

Embryonic day 15 (E15) rat embryos, obtained from anesthesized (100 $\mathrm{mg} / \mathrm{kg}$ ketamine plus $10 \mathrm{mg} / \mathrm{kg}$ xylazine) Sprague Dawley dams (Charles River Laboratories, Wilmington, MA) were dissected in ice-cold $\mathrm{Ca}^{2+}$, $\mathrm{Mg}^{2+}$-Free HBSS (CMF-HBSS; Cellgro; Mediatech, Herndon, VA) according to methodology described previously (Dunnett and Bjorklund, 1992). All animal use procedures were in accordance with the National Institutes of Health Guide for the Care and Use of Laboratory Animals and were approved by the Institutional Animal Care and Use committee at the University of Colorado Health Sciences Center. Ventral mesencephalon and striatum were sectioned from embryos and placed into ice-cold CMF-HBSS. The tissues were then washed three times with CMF-HBSS, mechanically dispersed (5-10 passes through a $1 \mathrm{ml}$ Pipetman tip) in fresh CMF-HBSS and, after trituration, centrifuged at $200-300 \times g$ for 5 $\min \left(10^{\circ} \mathrm{C}\right)$. The pellets were resuspended in $\sim 1 \mathrm{ml}$ of Ham's F12 media supplemented with $10 \%$ FBS, 2 mM L-glutamine, $100 \mu \mathrm{g} / \mathrm{ml}$ streptomycin, and $100 \mathrm{U} / \mathrm{ml}$ penicillin. Trypan blue exclusion was then used to quantify viable cells in a hemacytometer. A mixture of mesencephalic cells $\left(480,000\right.$ viable cells $\left./ \mathrm{cm}^{2}\right)$ and striatal cells $\left(120,000\right.$ cells $\left./ \mathrm{cm}^{2}\right)$ were plated into 12-well dishes containing $12 \mathrm{~mm}$ glass coverslips pretreated with polyethylenimine and into $1 \mathrm{ml}$ of media [mesencephalic-striatal (Mes-Str) cultures]. One milliliter of fresh media was added to the existing media $1 \mathrm{~d}$ after plating. Half of the media was replaced with fresh media every $2-3 \mathrm{~d}$ thereafter. The cultures were transfected in vitro on days 3-6.

An Effectene method (Qiagen, Hilden, Germany) was used for DNA transfection of HeLa, PAE cells, and Mes-Str cultures. HeLa and PAE cells stably expressing YFP-HA-DAT, HA-DAT, or untagged human DAT were selected by growing them in the presence of G418 $(400 \mu \mathrm{g} / \mathrm{ml})$. For microscopy, the cells were grown on glass coverslips and used in transient-expression experiments for experiments on the third day. For biochemical assays using isotope detection of HA11 the cells were plated into 48 -well dishes and used at near $100 \%$ confluency.

Conventional (forward) siRNA transfections were performed as described previously (Sorkina et al., 2005). Control nonspecific siRNAs verified for the absence of off-target effects, and labeled or unlabeled with Cy3 (Dharmacon, Lafayette, CO) were used in mock-transfections.

Antibody feeding endocytosis assay. The cells grown on glass coverslips or 96-well trays were incubated with $1-2 \mu \mathrm{g} / \mathrm{ml} \mathrm{HA11}$ in medium for $30-60 \mathrm{~min}$ at $18-20^{\circ} \mathrm{C}$, washed with binding medium [DMEM or F12; $0.1 \%$ bovine serum albumin (BSA)] and incubated at $37^{\circ} \mathrm{C}$ with DMSO or PMA $(1 \mu \mathrm{M})$ for the indicated times. The cells were then washed with ice-cold $\mathrm{Ca}^{2+}, \mathrm{Mg}^{2+}$-free PBS (CMF-PBS) and fixed with freshly prepared $4 \%$ paraformaldehyde for $15 \mathrm{~min}$ at room temperature. The cells were stained with secondary anti-mouse antibody conjugated with Cy5 ( $5 \mu \mathrm{g} / \mathrm{ml}$ ) in CMF-PBS containing 0.5\% BSA at room temperature for 45 min to occupy surface HA11. After washing, the cells were permeabilized by 5 min incubation in CMF-PBS containing 0.1\% Triton X-100/0.5\% BSA at room temperature, and then incubated with the same secondary conjugated with Cy3 $(1 \mu \mathrm{g} / \mathrm{ml})$ for 45 min to mark internalized HA11. Neuronal cultures were additionally stained with rabbit antibody to $\mathrm{TH}$ followed by secondary conjugated with Alexa-350. Both primary and secondary antibody solutions were precleared by centrifugation at $100,000 \times g$ for $20 \mathrm{~min}$. After staining, the coverslips were mounted in Mowiol (Calbiochem, La Jolla, CA).

Reversed-trasnfection siRNA screen. An siARRAY reversed-transfection (RTF) library with the SMARTpool reagents prealiquoted and predried in 96-well plates was prepared by Dharmacon to enable high-resolution analysis by fluorescence microscopy. The library was prepared in 96-well plates with $0.17 \mathrm{~mm}$ glass bottoms. Following the manufacture's protocol, the HeLa/YFP-HA-DAT cells were transfected by incubation with the transfection reagent and plating to the wells. The cells were grown under standard culture conditions for $3 \mathrm{~d}$ and assessed for endocytosis. To monitor endocytosis of the transferrin receptor, the cells were incubated with transferrin conjugated to fluorescein (Tfn-FC; Invitrogen) for $10 \mathrm{~min}$ at $37^{\circ} \mathrm{C}$. To assess the endocytosis of YFP-HA-DAT, the cells were incubated with 1-2 $\mu \mathrm{M}$ PMA for $30 \mathrm{~min}$ at $37^{\circ} \mathrm{C}$, and the endocytosis assay with HA11 was performed as described above.

Kinetic analysis of DA uptake by HA-DAT in PAE cells. The cells were grown in 24-well plates for $2 \mathrm{~d}$ and incubated with $\mathrm{HA} 11$ at room temperature as in endocytosis experiments. The cells were rinsed at $4^{\circ} \mathrm{C}$ and then assayed in Krebs-Ringer HEPES buffer (KRH; in mM: $120 \mathrm{NaCl}, 4.7$ $\mathrm{KCl}, 2.2 \mathrm{CaCl}_{2}, 1.2 \mathrm{Mg} \mathrm{SO}_{4}, 1.2 \mathrm{KH}_{2} \mathrm{PO}_{4}, 10$ glucose, 10 HEPES, pH 7.4) supplemented with $10 \mu \mathrm{M}$ pargyline, $10 \mu \mathrm{M}$ ascorbic acid, and $10 \mu \mathrm{M}$ catechol. Assays $(1 \mathrm{ml})$ included $50 \mathrm{~nm}\left[{ }^{3} \mathrm{H}\right] \mathrm{DA}$ (PerkinElmer Life Sciences, Boston, MA) and increasing concentrations of unlabeled DA $(0.05,0.5,1,5,10$, and $50 \mu \mathrm{M})$. Nonspecific $\left[{ }^{3} \mathrm{H}\right] \mathrm{DA}$ accumulation was determined in the presence of $1 \mathrm{~mm}$ cocaine $\mathrm{HCl}$ (NIDA/RTI International, Research Triangle Park, NC). After $10 \mathrm{~min}$ of incubation at $22^{\circ} \mathrm{C}$, uptake was terminated by quickly washing the cells three times with $1 \mathrm{ml}$ of ice-cold KRH. Cells were then solubilized in $0.5 \mathrm{ml}$ of $5 \%$ trichloroacetic acid for $60 \mathrm{~min}$ with gentle shaking. Accumulated $\left[{ }^{3} \mathrm{H}\right] \mathrm{DA}$ was determined by liquid scintillation counting. $K_{\mathrm{m}}$ and $V_{\max }$ values for $\left[{ }^{3} \mathrm{H}\right] \mathrm{DA}$ uptake were calculated with nonlinear regression fitting using GraphPad (San Diego, CA) Prism software. 


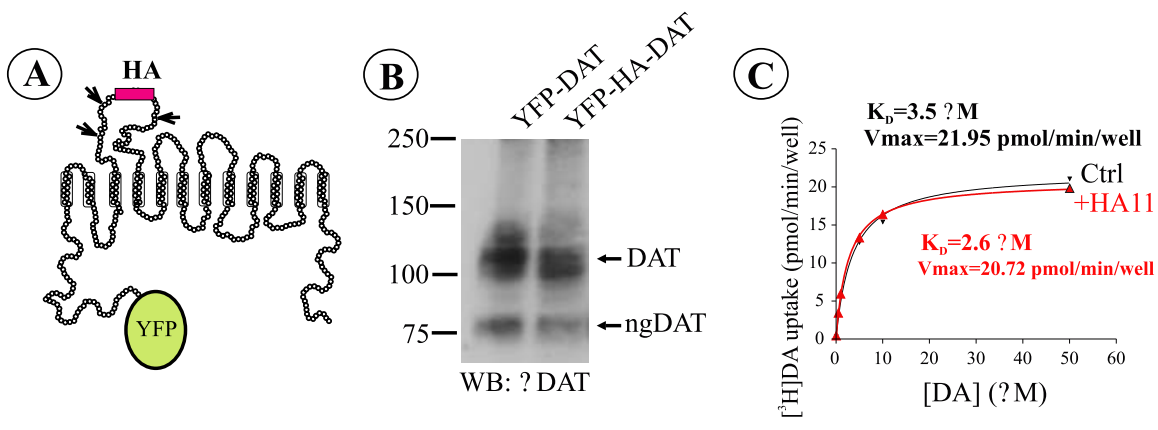

Figure 1. The schematic structure and characterization of YFP-HA-DAT. $\boldsymbol{A}$, The HA tag was placed in the second extracellular loop of human DAT, which was also tagged with YFP at the N terminus. Predicted $N$-glycosylation sites in the EL2 are indicated. $\boldsymbol{B}$, Western blot (WB) detection of YFP-DAT and YFP-HA-DAT in lysates of PAE cells. ngDAT, Nonglycosylated YFP-HA-DAT; $\alpha$ DAT, antibody to DAT. C, Kinetic parameters of [ ${ }^{3} \mathrm{H}$ ]DA uptake into PAE/YFP-HA-DAT cells incubated or not incubated (Ctrl) with HA11 were similar to each other and published values for PAE/DAT cells (Sorkina et al., 2003). $K_{D}$, Apparent affinity; Vmax, maximal velocity. The graph is representative of two experiments. Each data point represents an average of three wells.

\section{Results \\ Incorporation of an $\mathrm{HA}$ epitope into EL2 of DAT does not affect DAT function}

To develop a sensitive assay to monitor DAT endocytosis, we generated a functional DAT that has an antibodyaccessible extracellular epitope. To this end, residues 193-201 in the EL2 were converted into a sequence corresponding to nine amino acid residues of the HAepitope using DAT tagged on its $\mathrm{N}$ terminus with YFP as a template (Fig. $1 A$ ). The resulting YFP-HA-DAT was normally delivered to the plasma membrane when transiently or stably expressed in PAE and human cervical carcinoma HeLa cells.

We further characterized the functionality of YFP-HA-DAT when stably expressed in PAE cells. Figure $1 B$ shows that

Fluorescence microscopy. To obtain high resolution three-dimensional (3D) images of the cells, a $z$-stack of images was acquired through Cy5, Cy3, FITC (YFP fluorescence) and 4'-6-diamidino-2-phenylindole (Alexa-350) filter channels using a Marianas Imaging workstation and SlideBook 4.1 software (Intelligent Imaging Innovation, Denver, CO) as described previously (Sorkina et al., 2005). Typically, 30-34 serial twodimensional images were recorded at 200-300 nm intervals. All image acquisition settings were identical in each experiment. The $z$-stack of images obtained was deconvoluted using a modification of the constrained iteration method (Gaussian noise smoothing). Quantification of the relative amount of $\mathrm{Cy} 5$ and $\mathrm{Cy} 3$ fluorescence in the cell was performed using the statistics module of the SlideBook4.1. The backgroundsubtracted 3D images were segmented using a minimal intensity of YFP as a low threshold. New images were generated using this mask so that all voxels that did not contain YFP were assigned a value of zero. The integrated voxel intensity of $\mathrm{Cy} 5$ and $\mathrm{Cy} 3$ in each cell in the new image was then quantitated. In Mes-Str cultures, dopaminergic neurons were identified by TH staining.

Immunoprecipitation. The cells grown in $150 \mathrm{~mm}$ dishes were placed on ice and washed three times with CMF-PBS, and the proteins were solubilized in Triton X-100/glycerol/HEPES lysis buffer (Sorkina et al., 2005) supplemented with $10 \mathrm{~mm} \mathrm{~N}$-ethyl maleimide for $20 \mathrm{~min}$ at $4^{\circ} \mathrm{C}$. The lysate was then centrifuged at $100,000 \times g$ for 20 min to remove insoluble material. Lysates were incubated with appropriate antibodies overnight and antibodies were precipitated with protein A- or protein G-Sepharose. Immunoprecipitates and aliquots of cell lysates were denatured in sample buffer at $95^{\circ} \mathrm{C}$, resolved by electrophoresis, and probed with various antibodies followed by chemiluminescence detection as described previously (Sorkina et al., 2005).

Striatal slices were prepared from adult male Sprague Dawley rats. After decapitation, the brain was removed and washed in cold oxygenated artificial CSF (ACSF; $126 \mathrm{~mm} \mathrm{NaCl}, 2.9 \mathrm{~mm} \mathrm{KCl}, 1.5 \mathrm{~mm} \mathrm{MgCl}_{2}, 2.5$ $\mathrm{mm} \mathrm{CaCl}_{2}, 1.4 \mathrm{~mm} \mathrm{NaH}_{2} \mathrm{PO} 4,10 \mathrm{~mm}$ glucose, $25 \mathrm{~mm} \mathrm{NAHCO}_{3}, 200 \mu \mathrm{M}$ ascorbic acid, $\mathrm{pH} 7.4)$. Coronal slices $(400 \mu \mathrm{m})$ were cut with a vibratome and the striatum was dissected out in cold oxygenated ACSF. The striatal mini-slices were incubated in ACSF with DMSO or $1 \mu \mathrm{M}$ PMA for $30 \mathrm{~min}$ at $37^{\circ} \mathrm{C}$, washed with cold ACSF, and lysed as described above for cultured cells at $4^{\circ} \mathrm{C}$ for $1 \mathrm{~h}$. The lysates were centrifuged at $100,000 \times g$ for $40 \mathrm{~min}$, precleared with Protein A-Sepharose beads, and incubated with goat polyclonal DAT antibodies overnight followed by protein G-Sepharose precipitation. The immunoprecipitates and aliquots of lysates were denatured in the sample buffer at $42^{\circ} \mathrm{C}$.

Cell surface biotinylation. HeLa cells stably expressing untagged DAT [HeLa/DAT (Miranda et al., 2004)] were grown in 24- or 12-well plates, transfected with mock or Nedd4-2 siRNA, and then treated with DMSO or PMA for $30 \mathrm{~min}$ at $37^{\circ} \mathrm{C}$ as described above. Surface biotinylation assays were then performed as described previously (Sorkina et al., 2005).
YFP-HA-DAT immunoreactivity on Western blots was detected as two major species corresponding to the mature and endoplasmic-reticulum-localized immature DAT, essentially similar to the immunoreactive bands corresponding to YFPDAT. Kinetic measurements of $\left[{ }^{3} \mathrm{H}\right] \mathrm{DA}$ uptake into PAE/YFPHA-DAT cells (Fig. $1 C)$ yielded $K_{\mathrm{m}}(\sim 3 \mu \mathrm{M})$ and $V_{\max }(\sim 20$ $\mathrm{pmol} / \mathrm{min} /$ well) values that were very similar to values previously obtained in PAE cells expressing DAT or YFP-DAT (Sorkina et al., 2003). Moreover, when PAE/YFP-HA-DAT cells were incubated with monoclonal HA antibodies (HA11) to occupy all DATs exposed at the cell surface, the kinetic parameters of $\left[{ }^{3} \mathrm{H}\right] \mathrm{DA}$ uptake remained unchanged (Fig. 1C). Therefore, we concluded that YFP-HA-DAT is a fully functional DAT. In all assays, YFP-HA-DAT behaved similarly whether expressed in PAE or HeLa cells.

\section{Single-cell endocytosis assay using HA11 antibody}

Generation of functional YFP-HA-DAT allowed us to develop a single cell antibody uptake assay to follow DAT endocytosis. We found that at $4^{\circ} \mathrm{C}$, conditions that completely inhibit endocytosis and intracellular trafficking, HA11 did not efficiently bind to YFP-HA-DAT. Presumably, under these conditions the conformation adopted by the EL2 makes residues 193-201 inaccessible to antibodies. Therefore, to label transporters at the cell surface, PAE/YFP-HA-DAT cells were incubated with HA11 at room temperature $\left(18-22^{\circ} \mathrm{C}\right)$, conditions of minimal or no endocytosis (Fig. 2A). Subsequent incubation of cells at $37^{\circ} \mathrm{C}$ resulted in rapid endocytosis of HA11:YFP-HA-DAT complexes that were preformed at the cell surface. With this method, YFP-HA-DATs inserted into the plasma membrane during the $37^{\circ} \mathrm{C}$ chase were not labeled with HA11 and secondary fluorescent antibodies.

To distinguish surface from internalized HA11:HA-DAT complexes, formaldehyde-fixed cells were incubated with a saturating amount of secondary antibody labeled with Cy5 to label surface HA11. The cells were then permeabilized, and the internalized HA11-DATs were detected by staining with the same secondary antibodies but labeled with Cy3 (Fig. $2 \mathrm{~A}$ ). The ratio of Cy3 to Cy5 fluorescence calculated from three-dimensional images was used as the measure of YFP-HA-DAT endocytosis.

In the representative example of the endocytosis experiments with HA11 presented in Figure $2 B$, no significant Cy3 fluorescence was detected in cells incubated with antibodies at $20^{\circ} \mathrm{C}$, whereas Cy5 staining displayed a typical pattern of plasma mem- 
brane localization. The surface HA11: YFP-HA-DAT complexes stained by Cy5labeled antibodies were seen as numerous small clusters distributed throughout the plasma membrane and often concentrated at the cell edges. The YFP fluorescence that did not overlap with Cy3 or Cy5 fluorescence represents a pool of YFP-HA-DAT that was not present at the cell surface during antibody labeling and was located in the endoplasmic reticulum, Golgi, and possibly a subset of endosomes.

Subsequent $37^{\circ} \mathrm{C}$ incubation of the cells labeled with HA11 resulted in the appearance of HA11 in endosomes that were labeled with $\mathrm{Cy} 3$, but not with Cy5. In these endosomes Cy3 and YFP were highly colocalized (Fig. $2 \mathrm{~B}$ ). After a $37^{\circ} \mathrm{C}$ incubation, the ratio of $\mathrm{Cy} 3 / \mathrm{Cy} 5$ fluorescence increased twofold as compared with the ratio in cells not incubated at $37^{\circ} \mathrm{C}$, indicative of constitutive internalization of YFP-HADAT (Fig. 2C).

When cells were treated with PMA (1 $\mu \mathrm{M})$ to activate $\mathrm{PKC}$ for $30 \mathrm{~min}$ at $37^{\circ} \mathrm{C}$, conditions known to downregulate surface DAT, a significant amount of HA11 was accumulated in endosomes (Fig. $2 B$ ). PMA treatment increased the Cy3/Cy5 ratio by approximately threefold compared with constitutive endocytosis (Fig. 2C), which is consistent with an enhanced endocytosis of HA11:YFP-HA-DAT complexes. Under all conditions, very little, if any, colocalization of $\mathrm{Cy} 3$ and Cy5 fluorescence was observed. This indicates that binding of Cy3-conjugated secondary antibodies to surface HA11:YFP-HA-DAT, the complexes preoccupied by Cy5conjugated antibodies, was minimal. Therefore, most of Cy3 punctate fluorescence colocalized with YFP corresponded to internalized HA11:YFP-HA-DAT complexes. These complexes were inaccessible to Cy5-labeled secondary antibodies applied to nonpermeabilized cells. In summary, the data presented in Figure 2 demonstrated that an HA11-based assay can be used to monitor both constitutive and regulated endocytosis of DAT.

\section{YFP-HA-DAT endocytosis in dopaminergic neurons}

To analyze trafficking of YFP-HA-DAT in neurons, this construct was transiently expressed in primary dissociated rat E14E16 Mes-Str cocultures. It should be noted that the efficiency of transfection of dopaminergic neurons was very low. Thus, only a few neurons, which expressed both TH and YFP-HA-DAT, were found in each transfection experiment. An example of such a neuron prelabeled with $\mathrm{HA} 11$ at $20^{\circ} \mathrm{C}$ and then incubated at $37^{\circ} \mathrm{C}$ is presented in Figure 3. A number of YFP-containing intracellular compartments, which $\boldsymbol{B}$ (for details, see Results).
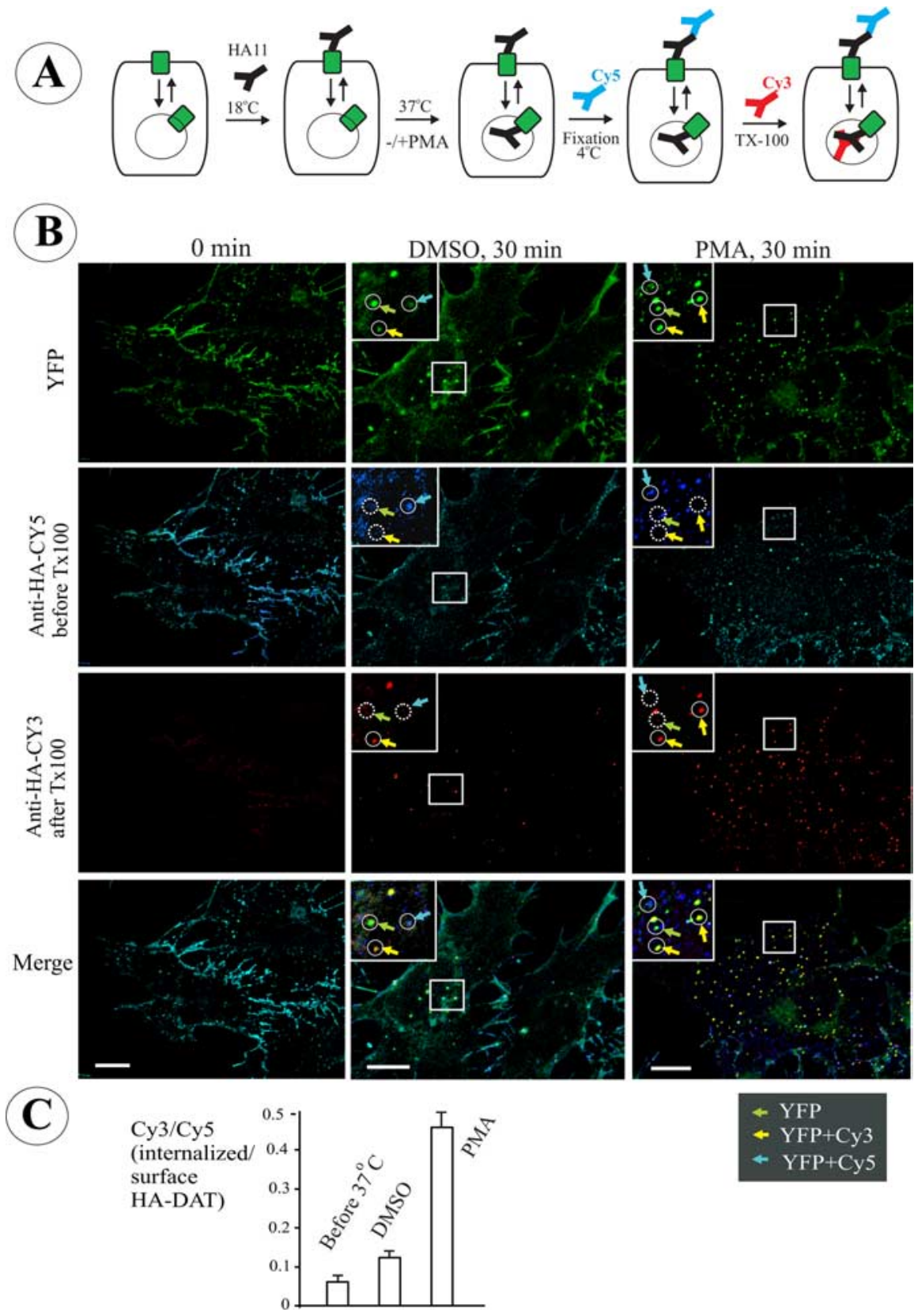

Figure 2. Single-cell endocytosis assay using HA11 antibody in PAE cells expressing YFP-HA-DAT. $A$, Schematics of the endocytosis assay using differential staining of surface and internalized HA11. The cells were incubated with $\mathrm{HA11}$ at $18-22^{\circ} \mathrm{C}$ for 30 min, washed, further incubated at $37^{\circ} \mathrm{C}$, and fixed. The nonpermeabilized cells were then stained with Cy5-tagged anti-mouse secondary lgG to occupy all surface HA11/YFP-HA-DAT complexes. After Triton X-100 (TX-100) permeabilization, the cells were incubated with the same secondary antibody but tagged with Cy3 to mark internalized HA11. $\boldsymbol{B}$, Representative images of PAE/YFP-HA-DAT in cells treated with vehicle (DMSO) or PMA $(1 \mu \mathrm{M})$ for 30 min at $37^{\circ} \mathrm{C}$ after prebinding of HA11. The staining with Cy5 (blue) and Cy3 (red) was performed as described in $\boldsymbol{A}$. The sum projection images of four consecutive optical sections are presented. Examples in high-magnification insets (single optical sections) demonstrate clusters and compartments containing YFP alone (total YFP-HA-DAT; green arrows), YFP colocalized with Cy5 (plasma membrane HA11; cyan arrows), and YFPcolocalized with Cy3 (internalized HA11; yellow arrows). Identical positions in the insets are indicated by circles. Solid and dashed lines show, respectively, the presence and absence of an endosome or a plasma membrane cluster within the circle. Scale bars, 10 $\mu \mathrm{m}$. C, Quantification of the ratio of internalized/surface YFP-HA-DAT (mean $\pm S D ; n=8-9$ cells) from the images presented in

were not colocalized with HA11 and likely represent endoplasmic reticulum/Golgi and endosomes, were seen in the cell soma and proximal parts of thick processes. Internalized HA11 (Cy3/YFPbut not Cy5-containing vesicles) was detected in the soma, dendrites, and axonal processes, indicative of constitutive en- 


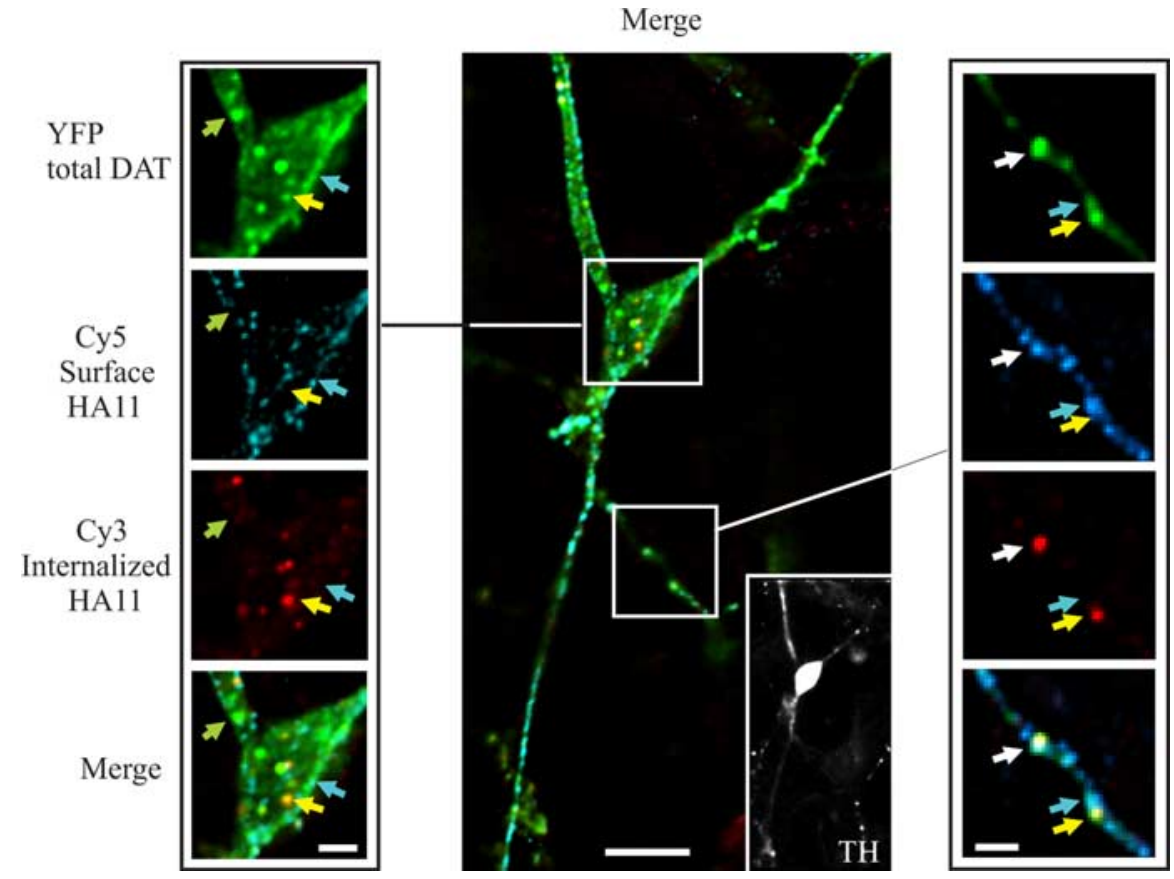

Figure 3. HA11 antibody uptake endocytosis assay in dopaminergic neurons. Mes-Str cultures were transfected with YFP-HADAT and assayed after $3 \mathrm{~d}$ (see Materials and Methods). The cells were incubated with HA11 for $60 \mathrm{~min}$ at $20^{\circ} \mathrm{C}$, washed, further incubated for $30 \mathrm{~min}$ at $37^{\circ} \mathrm{C}$, and fixed. The nonpermeabilized cells were stained with Cy5-tagged anti-mouse secondary lgG. After Triton X-100 permeabilization, the cells were incubated with the same secondary lgG tagged with Cy3 and simultaneously incubated with rabbit antibody to TH. Finally, the cells were incubated with secondary anti-rabbit lgG conjugated with Alexa-350. Az-stack of $30 x$-y images was acquired through four filter channels. The main image (scale bar, $10 \mu \mathrm{m}$ ) and high-magnification (scale bar, $3 \mu \mathrm{m}$ ) images of cell soma (left of the main image) represent optical section 10 . An inset at the right bottom corner of the main image represents an image of the TH staining. High-magnification images of a part of the processes (right of the main image) represent optical section 7 (scale bar, $3 \mu \mathrm{m}$ ). Green, cyan, and yellow arrows point to examples of compartments that contain, respectively, only YFP (total DAT), YFP colocalized with Cy5 (surface YFP-HA-DAT), and YFP colocalized with Cy3 (internalized HA11). A white arrow shows an example of an axonal varicosity with overlapping YFP, Cy5, and Cy3 fluorescence.

demonstrated the functionality of YFPHA-DAT in dopaminergic neurons and the utility of HA-DAT in visualization of constitutive DAT endocytosis in different parts of these neurons.

\section{RTF siRNA screening for proteins} important for DAT endocytosis

The endocytosis assay using HA11 allows accurate measurement of the amount of internalized and surface DAT, and this prompted us to use this assay in elucidation of the mechanisms of DAT endocytosis. We have recently developed a set of highly efficient siRNAs that are capable of knocking down the expression of several proteins participating in endocytosis (Huang et al., 2004). Expression of these siRNAs, or pools of siRNAs, depleted targets by $>90 \%$. In the case of several functionally redundant proteins, multiple duplexes or a pool of duplexes have effectively blocked clathrin-dependent endocytosis (Huang et al., 2004). By expanding the set of proteins targeted by the siRNA with other proteins implicated in endocytic trafficking, we have created an siRNA endocytosis library (a total of 52 human genes). The SMARTpool reagents targeting endocytic proteins were prealiquoted as an siARRAY RTF library in 96well plates (supplemental Fig. 1, available at www.jneurosci.org as supplemental material, for the layout of a 96-well plate). Importantly, in this siRNA library, highly

docytosis of YFP-HA-DAT in all parts of the neuron. In long axonal processes, endogenous DAT (data not shown) (see Fig. 8) and YFPHA-DAT (Fig. 3) were concentrated in multiple small $(\sim 1 \mu \mathrm{m})$ varicosities. Such varicosities often included overlapping Cy5, Cy3, and YFP fluorescent dots, which could not be spatially resolved (Fig. 3 ), and probably represented an entire synapse containing surface and internalized YFP-HA-DAT.

Treatment of neuronal cultures with PMA did not lead to any qualitative changes in YFP-HA-DAT distribution (data not shown). Because of the low efficiency of transiently expressed YFP-HA-DAT and high autofluorescence background in dopaminergic neurons, it was technically difficult to perform reliable quantifications of Cy3/Cy5 ratios in untreated and PMA-treated cells. However, visual inspection of images suggested that in contrast to non-neuronal expression systems, a relatively higher number of YFP-HA-DAT containing endosomes was seen in the soma and dendrites in untreated neurons compared with expression systems. Therefore, it is possible that on the background of the substantial endosomal pool of YFP-HA-DAT, PKC-induced acceleration of endocytosis did not lead to a further significant increase of this pool of YFP-HA-DAT. Furthermore, because internalized and surface DAT pools could not be resolved in most axonal varicosities, internalization rates in these neuronal compartments could not be visually estimated and could be measured only by calculating the Cy3/Cy5 ratios. Thus, improved expression efficiency of YFP-HA-DAT in dopaminergic neurons is needed before the analysis of endocytosis in neurons can fully benefit from an HA11 uptake assay. Nevertheless, data in Figure 3 homologous and possibly functionally redundant genes were loaded individually and in combination.

Because the siRNAs are targeted to human genes, HeLa cells stably expressing YFP-HA-DAT cells were used. HA11 uptake experiments in this cell line confirmed that the single-cell assay could readily differentiate endosomal and plasma membrane YFP-HA-DAT (supplemental Fig. 2, available at www.jneurosci.org as supplemental material). A biochemical assay using a secondary antibody labeled with ${ }^{125}$ I could be potentially used to measure the extent of endocytosis of HA11:YFP-HA-DAT complexes (supplemental Fig. 2, available at www.jneurosci.org as supplemental material). However, the sensitivity of this assay was not sufficient to use in a 96-well dish, and therefore a single-cell fluorescence assay was used.

The cells were plated into 96-well dishes containing the siRNA library and on the third day after transfection were assayed for PMA-induced endocytosis as described in Figure 2 and supplemental Figure 2 (available at www.jneurosci.org as supplemental material). The efficiency of YFP-HA-DAT:HA11 endocytosis was evaluated in a blind manner by comparing the amount of Cy5 (surface) and Cy3 (internalized) fluorescence. As a measure for the effectiveness of the siRNAs, the effect of siRNAs on endocytosis of Tfn-FC, a classical marker of clathrin-dependent internalization, was analyzed in parallel.

As shown in Figure $4 A$, the relative amount of Cy3 fluorescence was dramatically decreased as compared with controls by several siRNAs. In particular, the screen confirmed the importance of clathrin heavy chain (CHC) and dynamin for DAT en- 
docytosis in HeLa cells (Fig. $4 B$ ), which we had previously demonstrated using conventional ("forward") siRNA transfections in PAE cells (Sorkina et al., 2005). The same proteins were found to be critical for Tfn-FC endocytosis (Boese et al., 2006). Knockdown of two or all three Rab5 isoforms also resulted in the blockade of both Tfn-FC and YFP-HA-DAT endocytosis (Fig. $4 B$ ). Interestingly, several siRNAs inhibited YFP-HA-DAT, but not TfnFC, endocytosis. Knockdown of E3 ubiquitin ligase Nedd4L (also known as Nedd4-2), alone or in combination with Nedd4 (but not knockdown of Nedd4 alone), resulted in a dramatic block of HA11 endocytosis (Fig. 4A,B). Furthermore, several combinations of siRNAs to epsin-1 together with Eps15 and Eps15R also led to a significantly reduced accumulation of HA11 in endosomes, although the same siRNAs had only minor effect on transferrin endocytosis (Fig. 4C). Interestingly, epsin, Eps15, and Eps15R contain ubiquitin-interacting motifs that have been implicated in the recognition of ubiquitylated cargo (Hicke et al., 2005). Altogether, the siRNA analysis confirmed that clathrin-mediated endocytosis is the main pathway of PKC-induced DAT internalization and suggested the importance of proteins involved in ubiquitination and the ubiquitin-recognition system in PKC-dependent endocytosis of DAT.

\section{Nedd4-2 is essential for \\ DAT ubiquitination}

Two types of proteins were revealed by the siRNA screen as candidates for critical functions in DAT endocytosis: first, the clathrin coat assessory proteins, like epsin and the highly homologous Eps 15 and Eps15R, and second, an E3 ubiquitin ligase Nedd4-2. Epsin and Eps15/15R have been implicated in regulating the steps of clathrin pit and vesicle formation not directly related to cargo recruitment or specific to a particular cargo (Cupers et al., 1997; Benmerah et al., 1999; Morgan et al., 2003).

However, the potential role of Nedd4-2 was tempting to explore in light of our recent finding of PKC-dependent and constitutive DAT ubiquitination (Miranda et al., 2005). Nedd4-2 is an HECT (homologous to the E6-accessory protein $\mathrm{C}$ terminus) domain containing ubiquitin ligase. Nedd $4-2$ has been implicated in regulation of endocytosis of several transmembrane proteins, including voltage-gated epithelial sodium channels and a glutamate transporter (Kamynina et al., 2001; Boehmer et al., 2003c; Flores et al., 2003). Thus, we further focused on the role of Nedd4-2 in DAT regulation.

To elucidate the function of Nedd4-2 in DAT endocytosis, forward siRNA transfection experiments with human Nedd4-2 siRNA were performed. The SMARTpool of Nedd4-2 siRNA that was used in the RTF screen reduced the amount of Nedd $4-2$

(C)

\section{YFP-HA-DAT}

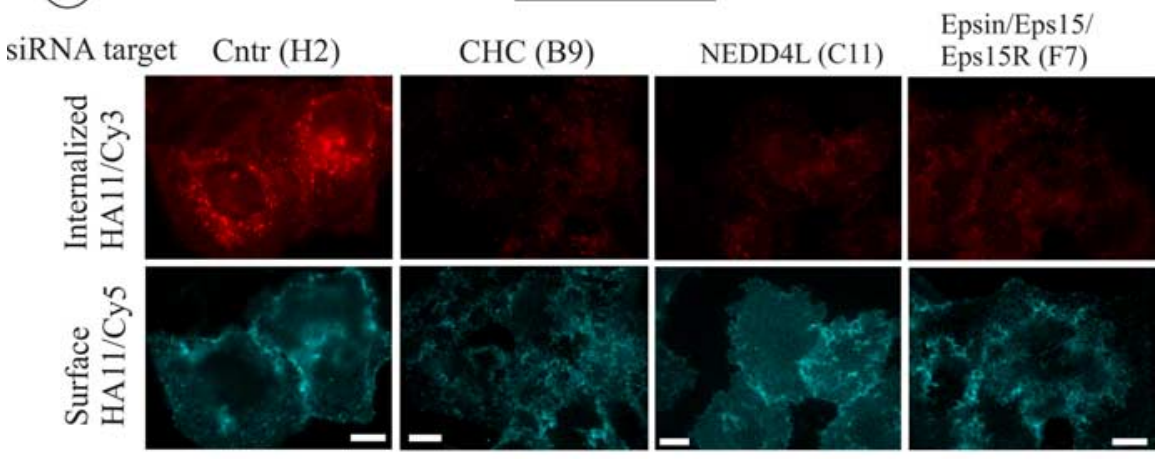

\begin{tabular}{|l|c|c|}
\hline B & $\begin{array}{c}\text { YFP-HA-DAT } \\
\text { endocytosis }\end{array}$ & $\begin{array}{l}\text { Tfn-FC } \\
\text { endocytosis }\end{array}$ \\
\hline CHC & - & - \\
Dynamin II & - & - \\
NEDD4L & - & +++ \\
NEDD4L+NEDD4 & - & +++ \\
Epsin1+Eps15 & + & ++ \\
Epsin1+Eps15+Eps15R & $(+)$ & ++ \\
Rab5a+Rab5c & - & ++ \\
Rab5a+Rab5b+Rab5c & - & - \\
\hline
\end{tabular}
$\underline{\text { Tfn-FC }}$
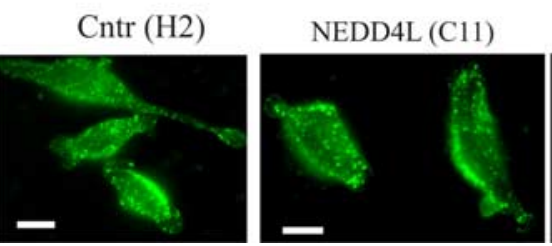

Epsin/Eps15/

Eps15R (F7)

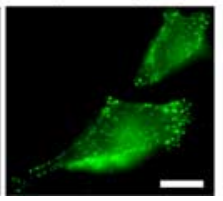

Figure 4. RTF siRNA library screening with HeLa/YFP-HA-DAT cells. HeLa/YFP-HA-DAT cells were plated into 96-well plates containing individual or combinations of SMARTpools of siRNA duplexes. After $3 \mathrm{~d}$, the cells were incubated with HA11 for 30 min secondary (surface), then permeabilized and further stained with (y-3-labeled secondary (internalized). In a parallel screen, the cells were incubated with $1 \mu \mathrm{g} / \mathrm{ml}$ Tfn-FC for $5 \mathrm{~min}$ at $37^{\circ} \mathrm{C}$. $\boldsymbol{A}$, Representative images of YFP-HA-DAT endocytosis in cells $0-500$ for Cy3 for all images. Scale bars, $10 \mu \mathrm{m}$. B, Summary of the results based on the visual examination of two independent efficiency of YFP-HA-DAT and Tfn-FC endocytosis was graded from maximum $(+++)$ (control and mock-transfected cells) to minimum ( - ; CHC-depleted cells). C, Representative images of Tfn-FC endocytosis in cells transfected with indicated siRNAs. Coordinates of wells are in parentheses. The intensity scale is $0-1000$ for all images. Scale bars, $10 \mu \mathrm{m}$.

protein by $\sim 90 \%$ in HeLa/YFP-HA-DAT cells (Fig. $5 B$ ). The endocytosis assay using HA11 demonstrated that forward knockdown of Nedd4-2 substantially reduced the amount of Cy3detected HA11 in endosomes, thus confirming the inhibitory effect of siRNA discovered in the RTF siRNA screen on PKCdependent DAT endocytosis (Fig. 5A). The importance of Nedd4-2 in PKC-induced DAT endocytosis was confirmed in HeLa cells stably expressing untagged wild-type DAT. In these experiments, a surface biotinylation assay was used to demonstrate that depletion of Nedd4-2 abolishes PMA-induced downregulation of surface-exposed DAT (Fig. 6). Interestingly, knockdown of Nedd4-2 resulted in statistically significant upregulation of steady-state levels of surface DAT (Fig. 6D), suggesting that Nedd4-2 may regulate constitutive endocytosis 


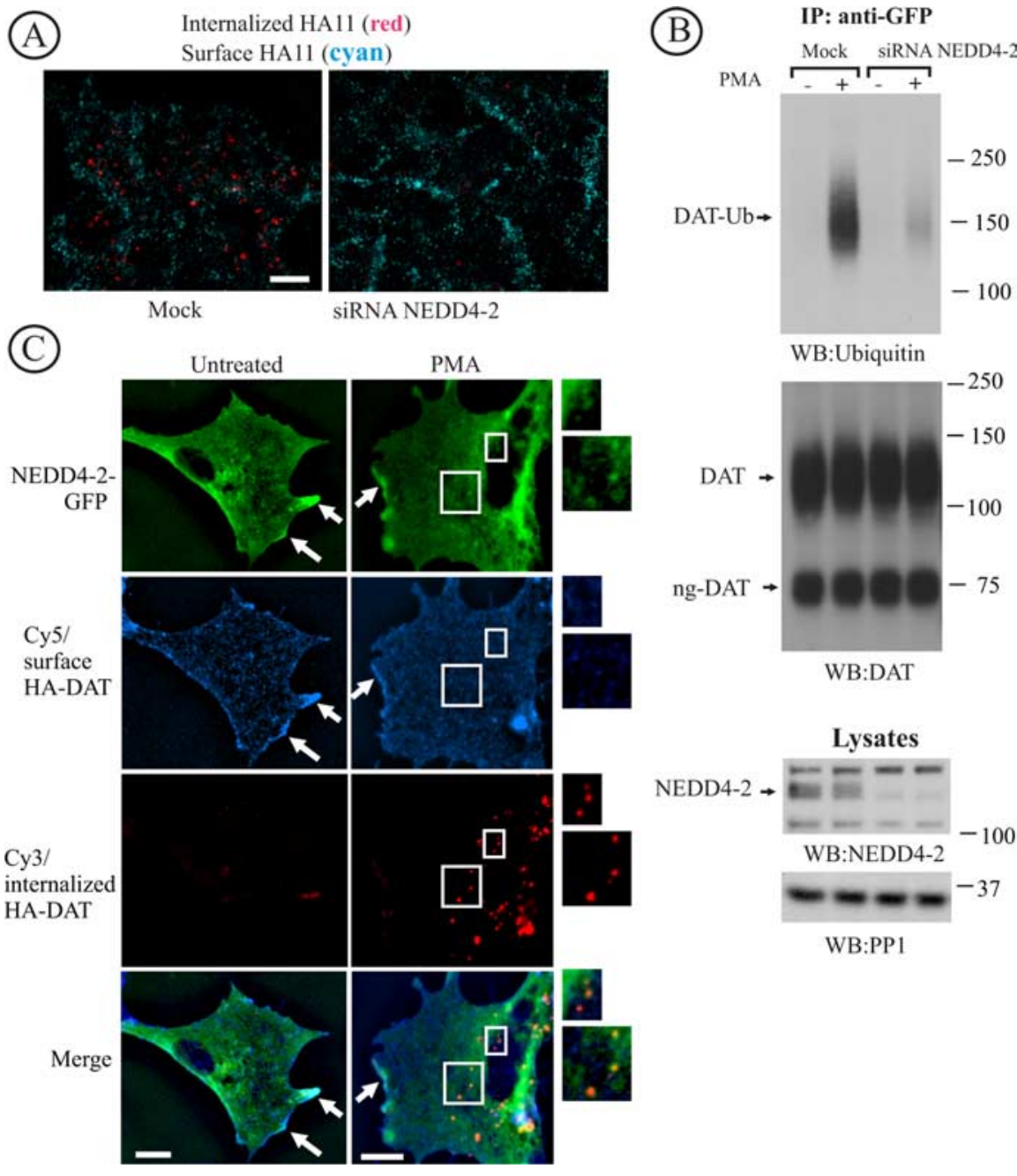

Figure 5. Nedd4 -2 is essential for DAT endocytosis and ubiquitination. $\boldsymbol{A}$, HeLa/YFP-HA-DAT cells were transfected with Nedd4-2 SMARTpool siRNA using conventional forward transfection. The HA11 endocytosis was examined as in Figure 2. Identical intensity settings for fluorescence were used in both images. Scale bars, $10 \mu \mathrm{m}$. B, YFP-HA-DAT was immunoprecipitated from mock- and siRNA-transfected HeLa/YFP-HA-DAT cells, and the immunoprecipitates and aliquots of lysates were probed with antibodies to Nedd4-2, ubiquitin, and DAT. DAT-Ub, Ubiquitinated DAT; ng-DAT, nonglycosylated DAT. The lysates were also blotted with antibodies to an unrelated protein (PP1) to control for sample loading. C, PAE/HA-DAT cells were transfected with Nedd4 -2-GFP and assayed on the third day. The cells were incubated with HA11 for 60 min at $20^{\circ} \mathrm{C}$, washed and fixed, or further incubated with $1 \mu \mathrm{M}$ PMA for $30 \mathrm{~min}$ at $37^{\circ} \mathrm{C}$ and then fixed. After fixation, the surface and internalized HA-DAT were stained with Cy5 and Cy3 secondary antibodies as described in Figure 2. The images represent a z-sum projection of three optical sections. Arrows show colocalization of HA-DAT and Nedd4-2-GFP in plasma membrane ruffles and cell edges. Insets represent highmagnification images of the cell regions marked by rectangles demonstrating colocalization of Nedd4-GFP and HA11/HA-DAT complexes in endosomes (Cy3 fluorescence). Scale bars, $10 \mu \mathrm{m}$.

and/or turnover of DAT. Most important, depletion of Nedd4-2 also resulted in a dramatic reduction in the amount of ubiquitin detected by Western blotting of YFP-HA-DAT immunoprecipitates that were recovered from cells treated with PMA (Fig. 5B). The small amount of ubiquitinated DAT in Nedd4-2 depleted cells was likely attributable to the presence of residual Nedd4-2. There was also a small reduction in the basal ubiquitin signal in DAT immunoprecipitates recovered from vehicle-treated cells. Thus, the data in Figure 5, $A$ and $B$, strongly indicate that Nedd4-2 is essential for PKC-dependent DAT ubiquitination and endocytosis.

To examine whether Nedd4-2 can be found in the same cellular locations as DAT, PAE cells stably expressing HA-DAT (full-length DAT tagged with Flag/Hisx10 at the N terminus and HA in the EL2) were transfected with Nedd4-2-GFP. In control experiments, colabeling of PAE/HA-DAT cells with HA11 and DAT antibodies revealed essentially complete colocalization of two antibodies (data not shown). The PAE/HA-DAT cells transiently expressing Nedd4-2-GFP were incubated with HA11 at $20^{\circ} \mathrm{C}$ and subsequently at $37^{\circ} \mathrm{C}$ with or without PMA for $30 \mathrm{~min}$, followed by the detection of surface and internalized HA11 by secondary Cy5- and Cy3-labeled antibodies, respectively, as described in Figure 2. As shown in Figure 5C, Nedd42-GFP was distributed throughout the cytosol and plasma membrane of the cells and was also seen in the intracellular vesicular compartments. Colocalization of Nedd4-2-GFP and HA11 was clearly seen at the cell edges and plasma membrane ruffles (Fig. 5C). In PMA-treated cells, HA11 and Nedd4-2-GFP were partially colocalized in endosomes (Fig. 5C). Furthermore, coimmunoprecipitation experiments revealed association of endogenous Nedd4-2 with YFP-HA-DAT in lysates of HeLa cells treated with vehicle or PMA (Fig. $7 B$ ). Together, data in Figures 5C and $7 B$ demonstrated that Nedd $4-2$ may directly or indirectly associate with DAT and participate in DAT ubiquitination at the plasma membrane and endosomes.

\section{Epsin and Eps15/R are involved in DAT endocytosis}

To confirm the inhibitory effects of epsin/ Eps15/Eps15R siRNAs discovered in the RTF screen, forward siRNA transfection of HeLa/YFP-HA-DAT cells was performed using a combination of specific siRNA duplexes (Huang et al., 2004) or siRNA SMARTpools. Figure $7 A$ shows that the mixture of three SMARTpools was the most effective because it significantly (by $\sim 80 \%$ ) depleted Eps15 and epsin-1, and partially depleted Eps15R. Both triple combinations, (1) individual Eps15/epsin duplexes with Eps15R siRNA pool and (2) the mixture of three SMARTpools, had an inhibitory effect on YFP-HA-DAT endocytosis measured using an HA11 uptake assay, although the latter mixture resulted in maximal inhibition (Fig. 7B). Quantification of the ratio of $\mathrm{Cy} 3$ and $\mathrm{Cy} 5$ fluorescence from experiments presented in Figure $7 B$ yielded threefold reduction of this ratio in cells depleted of Eps15/15R and epsin by the mixture of siRNA pools (Cy3/Cy5, $0.21 \pm 0.05 ; n=10)$ as compared with mocktransfected cells (Cy3/Cy5, $0.75 \pm 0.24 ; n=10)$.

We next tested whether Eps15 and epsin-1 interacted with DAT. To this end, YFP-HA-DAT was immunoprecipitated from HeLa cells treated with vehicle or PMA, and the presence of endogenous epsin-1 and Eps15 was probed by Western blotting. The presence of Eps15R, a homolog of Eps15, was not examined because this protein is present in multiple splicing variants (Fig. $7 A$ ) and it is technically difficult to interpret the specificity of detection of these multiple species. As shown in Figure $7 B$, both 


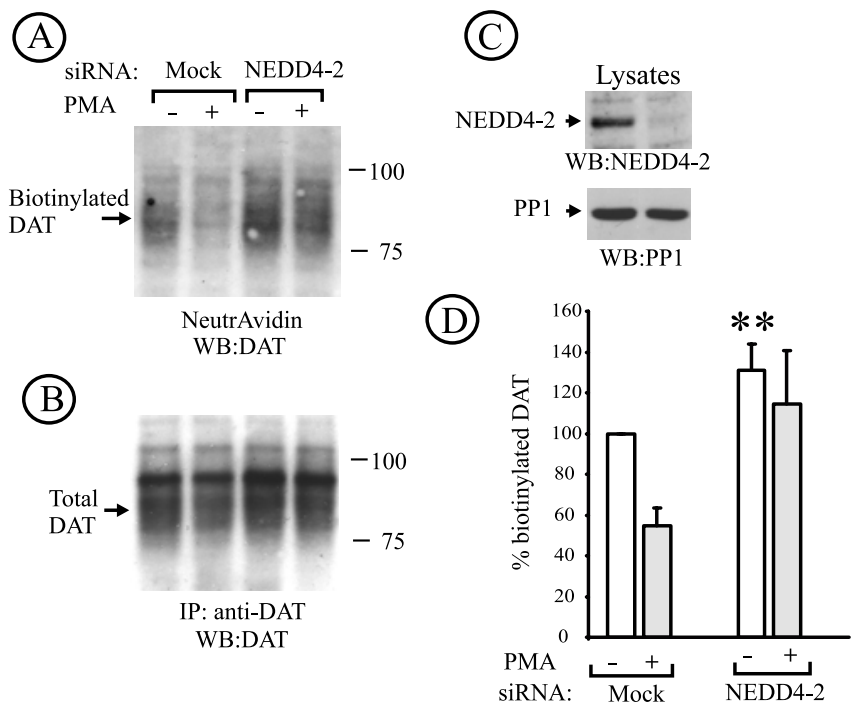

Figure 6. Nedd4 -2 siRNA reduces PKC-dependent downregulation of untagged DAT. $\boldsymbol{A}$, $\mathrm{HeLa} / \mathrm{DAT}$ cells that were transfected twice with control (mock) or Nedd4 -2 siRNA and used in experiments $6 \mathrm{~d}$ after the first transfection. The cells were incubated with vehicle or PMA as in Figure 2. The cells were then surface biotinylated and lysed, and the biotinylated proteins were pulled-down by NeutrAvidin agarose. Nonbiotinylated DAT was immunoprecipitated with rat anti-DAT from supernatants of NeutrAvidin agarose $(\boldsymbol{B})$. DAT was detected by Western blotting using rat anti-DAT in NeutrAvidin precipitates $(\boldsymbol{A})$ and DAT immunoprecipitates $(\boldsymbol{B})$, whereas Nedd4 -2 was probed in aliquots of lysates $(\boldsymbol{C})$. The lysates were also blotted with antibodies to an unrelated protein (PP1) to control for sample loading (C). Quantification of the amount of biotinylated DAT was performed by densitometry $(\boldsymbol{D})$. The data represent averaged values from five experiments ( $\pm S D$ ) and are expressed as percentage of the amount of biotinylated DAT in vehicle-treated, mock-transfected cells. ${ }^{* *} p<0.05$ compared with mock-transfected, vehicletreated cells.

epsin and Eps15 were specifically coimmunoprecipitated with YFP-HA-DAT. In the representative experiment presented in Figure $7 B$, there was a slightly larger amount of epsin and Eps15, as well as Nedd4-2 coimmunoprecipitated in cells treated with PMA. However, in a number of other experiments the extent of immunoprecipitation was independent on PKC activation (data not shown). Altogether, the data in Figure 7 suggest that epsin and Eps15 (and possibly Eps15R) participate in PKC-dependent, and possibly constitutive, endocytosis of DAT by directly or indirectly interacting with DAT during internalization and/or endosomal sorting.

\section{Localization and interactions of endogenous rat DAT}

To examine whether the mechanisms of DAT endocytosis and DAT interactions discovered in expression systems (Figs. 4-7) reflect those in dopaminergic neurons, we first inspected localization of endogenous rat DAT relative to coated pits in Mes-Str cultures. Clathrin-coated pits could be resolved in cell soma and large axonal widenings, which were occasionally observed in DA neurons. Immunofluorescence analysis under steady-state conditions revealed DAT located in punctuate structures labeled by CHC (data not shown) and Eps15 (Fig. 8A), suggesting constitutive localization of a pool of rat DAT in clathrin-coated pits containing Eps15.

Whereas primary neuronal cultures were used for single-cell analysis, the amount of DAT protein in these cultures was not sufficient for biochemical analyses. Therefore, to examine whether endogenous neuronal DAT is capable of interaction with Nedd4-2, epsin, and Eps15, DAT was immunoprecipitated from naive adult rat striatal slices treated or untreated with PMA (Fig.
$8 \mathrm{~B})$. Rat DAT was detected as a $\sim 70 \mathrm{kDa}$ band and occasionally as a high-molecular weight species, corresponding to mature glycosylated monomeric DAT and aggregated DAT, respectively. The immature unglycosylated form of DAT was not found in the striatum. Whereas ubiquitinated DAT recovered from HeLa cells migrated on SDS-PAGE as a single band (Fig. 5), the ubiquitin immunoreactivity associated with DAT immunoprecipitates from rat brain was detected as a large smear or as several slowmigrating bands (Fig. 8, supplemental Fig. 3, available at www. jneurosci.org as supplemental material). Such differential appearance of ubiquitin immunoreactivity in DAT immunoprecipitates may be indicative of a higher extent of polyubiquitination of endogenous DAT, as compared with heterologously expressed DAT. It could also reflect differences in the procedures used for DAT precipitation from cells and brain tissue (see Materials and Methods).

Interestingly, in most experiments PMA did not cause (Fig. $8 B$ ) or only slightly increased ubiquitination of striatal DAT (supplemental Fig. 3, available at www.jneurosci.org as supplemental material). It is possible that PMA did not efficiently penetrate through the slice tissue. Alternatively, PKC may be constitutively activated in striatal DA neurons and additional activation of PKC by PMA then might not result in an increased DAT ubiquitination. Nevertheless, specific coimmunoprecipitation of DAT and Nedd4-2, which is present as two alternatively spliced forms in rodent brain (Itani et al., 2003), was observed (Fig. 8C). Likewise, epsin and Eps15 were coimmunoprecipitated with DAT antibodies, but not with nonspecific IgG. Together, the data in Figure 8 indicate an interaction of rat DAT with Nedd4-2, epsin, and Eps15. In all experiments in HeLa cells and rat brain, the extent of coimmunoprecipitation of all three proteins with DAT was relatively small, indicative of relatively weak and/or indirect interactions. It should be also noted that at any given time only a small fraction of the total DAT pool can be present in coated pits/vesicles because of short residency time of cargo in these compartments, and therefore theoretically only a small pool of DAT is expected to be transiently complexed with adaptor proteins.

\section{Discussion}

In this study, we prepared and characterized a novel DAT mutant containing an epitope-tag in EL2. To our knowledge, plasma membrane transporters of this family have not been previously epitope-tagged in the extracellular loops. All of our attempts to introduce epitopes in other parts of EL2 or into EL6 produced mutants that did not efficiently exit the endoplasmic reticulum. Likewise, we have not been able to find conditions under which an antibody to the C-terminal part of EL2 (Ciliax et al., 1995) binds DAT in living cells, suggesting that this part of the loop is not assessable under physiological conditions. Surprisingly, whereas the central part of EL2 contains $N$-glycosylation sites, the accessibility of this HA sequence to an HA11 antibody suggests that this region is exposed under physiological conditions. Multiple amino acid substitutions appeared not to affect DAT glycosylation because the insertion of HA did not change the apparent molecular mass of mature YFP-DAT (Fig. 1). Recently, the x-ray structure of the homologous bacterial leucine transporter was published (Yamashita et al., 2005). However, the sequence corresponding to residues 193-201 of DAT is not present in the bacterial leucine transporter, and structural information for this part of the DAT molecule is not available. Nonetheless, the strong temperature dependence of HA11 binding to HA-EL2 is sugges- 


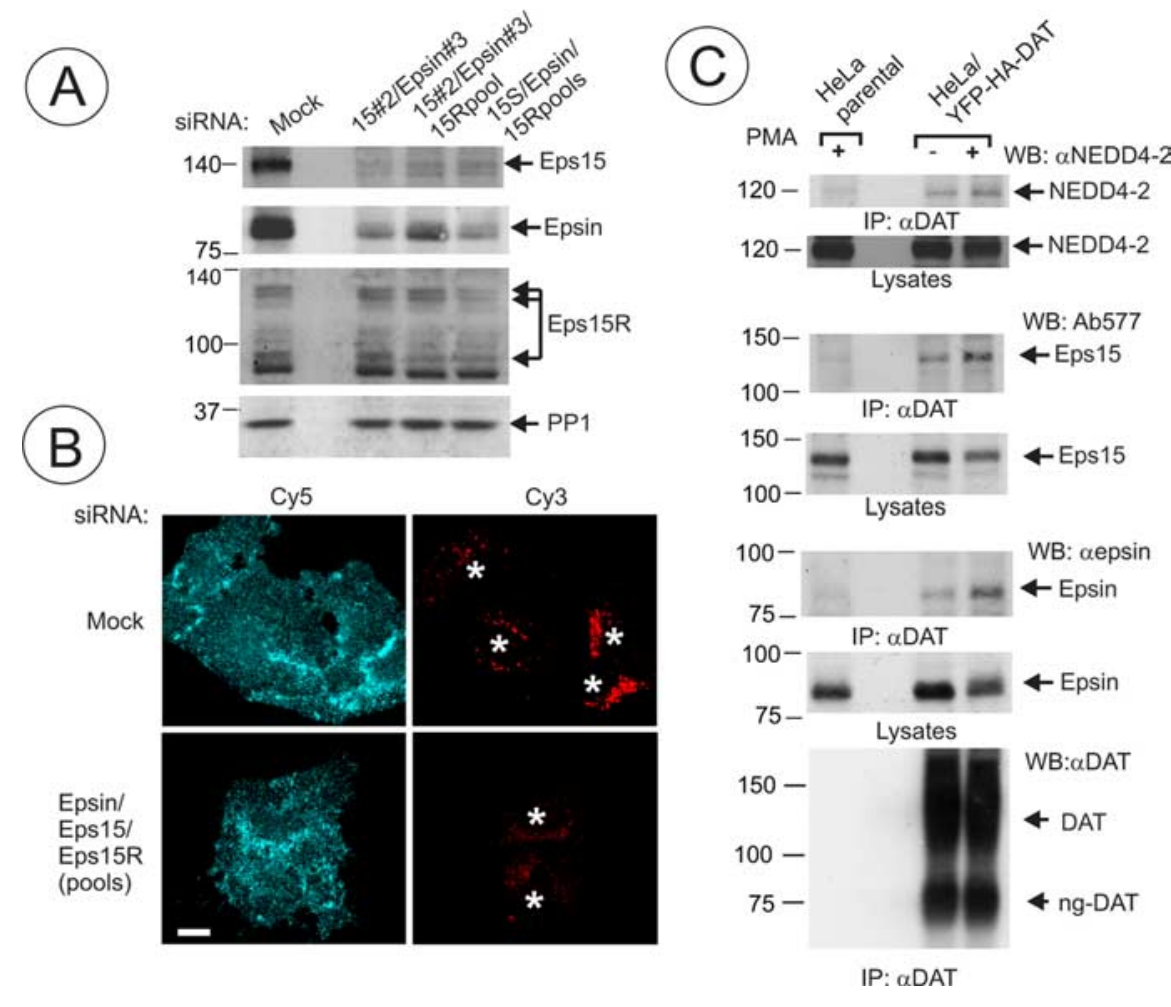

Figure 7. Epsin and Eps15/Eps15R are involved in DAT endocytosis and coimmunoprecipitated with DAT. A, HeLa/YFP-HA-DAT cells were mock transfected or transfected with the mixture of epsin-1 and Eps15 siRNA SMARTpools, or epsin-1 siRNA duplex 2 , Eps15 siRNA duplex 3 (Huang et al., 2004), and Eps15R SMARTpool, or with a mixture of SMARTpools of all three siRNAs using conventional forward transfection. Cell lysates were probed with antibodies to Eps15, Esp15R, and epsin-1 to determine the extent of depletion of proteins, and with antibodies to an unrelated protein (PP1) to control for sample loading. $\boldsymbol{B}, \mathrm{HA} 11$ endocytosis was examined as in Figure 2. Identical intensity settings for Cy 5 or Cy 3 fluorescence were used to generate images of mockversus specific siRNA-transfected cells. The sum projection images of three consecutive optical sections are presented. Scale bars, $10 \mu \mathrm{m}$. Asterisks indicate positions of cell nuclei. C, YFP-HA-DAT was immunoprecipitated from parental HeLa or HeLa/YFP-HADAT cells ( $\pm P M A)$, and the immunoprecipitates and lysates were probed with antibodies to Nedd4-2, Eps15 and epsin-1, and then with antibodies to DAT.

tive of substantial temperature-dependent conformational changes in the EL2.

Generation of an HA-tagged DAT allowed us to develop endocytosis assays based on HA11 antibody binding and uptake. We focused on a quantitative single-cell assay (Fig. 2) because of the potential for this assay to be used to analyze DAT trafficking in dopaminergic neurons. HA11 binds to the HA epitope with very high affinity; and even a very large excess of antigenic peptide, unlabeled HA11, or acidic $\mathrm{pH}$ treatment did not dissociate the Cy3-labeled HA11 antibody from YFP-HA-DAT (data not shown). Resistance to the low $\mathrm{pH}$ treatment also indicated that internalized HA11 does not dissociate from HA-DAT in endosomes and lysosomes.

Using this HA11-based endocytosis assay, a large-scale RNAi library screening analysis of DAT endocytosis was performed. The validity of the RTF siRNA screen was confirmed by the strong inhibitory effects of siRNAs to CHC and dynamin II on YFP-HADAT and transferrin endocytosis. Although the efficiencies of protein depletion of a number of siRNA SMARTpools have been validated previously in our published (Jiang and Sorkin, 2003; Huang et al., 2004) and unpublished work, a number of siRNAs have not been experimentally tested for their depletion efficiency and gene silencing. Thus, the absence of a detectable effect of an siRNA in the RTF screen does not necessarily mean that a corresponding target protein is not involved in endocytosis. However, the library provided several positive hits, such as Nedd4-2 that strongly indicates the importance of this protein in PKC-dependent endocytosis of DAT. Interestingly, we found that the effects of double- and multiple- siRNA knockdowns are often more pronounced in the RTF than in the forwardtransfection method. For instance, a substantially larger extent of inhibition of transferrin endocytosis was observed in the RTF plates by Rab5a/b/c knockdowns than was observed in the conventional knockdowns (Huang et al., 2004).

Identification here of Nedd $4-2$ as a protein important for DAT endocytosis is consistent with the demonstration of constitutive and PKC-dependent ubiquitination of DAT in our previous work (Miranda et al., 2005). This finding is also consistent with the accumulating evidence for the critical role of this ubiquitin ligase in the regulation of localization and trafficking of channels and transporters (Flores et al., 2003; Thomas and Itani, 2004). The observation of the dramatic deubiquitination of DAT in cells depleted of Nedd4-2 and the Nedd4-2 interaction with DAT suggests that Nedd4-2 is likely to be the E3 ubiquitin ligase for DAT. Moreover, siRNAs to other E3 ligases in our screen, such as Nedd 4 and Cbls, did not affect DAT endocytosis. This is in agreement with the specific role of Nedd4-2, but not the highly homologous Nedd4 or WW2, in regulation of endocytosis and ubiquitination of epithelial sodium channels (Snyder et al., 2004; Rougier et al., 2005). The WW domain of Nedd4-2 is known to recognize PPxY sequence motifs in its targets (Rougier et al., 2005). However, such sequences are not present in DAT N and C termini. Mutation of the PSLY sequence in the fifth intracellular loop of DAT yielded a transporter mutant that was unable to exit from the endoplasmic reticulum (data not shown). It is possible that Nedd4-2 can either use unconventional mechanisms to bind DAT or that it indirectly interacts with DAT. The possibility cannot be ruled out that Nedd4-2 regulates the activity of another E3 ligase specific for DAT. Nedd4-2 is known to be negatively regulated by phosphorylation (Debonneville et al., 2001; Boehmer et al., 2003a,b). Based on our experiments, PKC activation does not lead to elevated association of Nedd4-2 with DAT but may directly increase Nedd4-2 activity or, alternatively, allow accessibility of ubiquitination sites in the DAT molecule for Nedd4-2 or a Nedd4-2-regulated ubiquitin ligase.

The functions of epsin and Eps15/Eps15R in endocytosis have been extensively studied but are not well understood. In yeast cells, epsins appear to be essential for internalization of ubiquitinated cargo (Shih et al., 2002). However, siRNA knockdowns of epsin and Eps15/15R in mammalian cells produced variable results. Single knockdowns of these genes did not affect clathrinmediated endocytosis, whereas triple knockdowns partially inhibited endocytosis of epidermal growth factor and transferrin receptors (Huang et al., 2004; Sigismund et al., 2005). A recent study implicated the ubiquitin-adaptor function of epsin/Eps15/ 
Eps15R in caveolae-mediated endocytosis (Sigismund et al., 2005). In summary, whereas the role of these proteins as ubiquitin adaptors in coated pits in mammalian cells has been proposed, it is not experimentally established. Likewise, a number of general functions during the formation of coated pits and vesicles have been ascribed to these proteins but no consensus has been reached regarding these functions (Benmerah et al., 1999; Aguilar et al., 2003; Morgan et al., 2003; McMahon and Mills, 2004). Based on siRNA, colocalization, and immunoprecipitation data (Figs. 7, 8), epsin and Eps15/15R may participate in PKC-dependent, and possibly constitutive, endocytosis of DAT by binding to DAT via its ubiquitin moieties or other interaction motifs, either directly or through an additional adaptor protein. Elucidation of the precise function of these proteins in DAT endocytosis will require a detailed structure-function analysis combined with an efficient multigene siRNA silencing.

Several lines of evidence suggest that Nedd4-2 and clathrin adaptors bearing ubiquitin interaction motifs may be involved in DAT endocytosis and endosomal sorting in DA neurons. First, DAT is readily detected in clathrin-coated pits/ vesicles in DA neurons (Fig. 8A). Second, Nedd4-2 is ubiquitously expressed ( $\mathrm{Ku}$ mar et al., 1997) and present in rat striatum (Fig. 8 B). Third, Nedd $4-2$, as well as Eps15 and epsin, are associated with DAT in the brain (Fig. $8 \mathrm{~B}$ ). Although we have not been able to consistently observe PMA-induced DAT ubiquitination in rat striatal slices (Fig. 8, supplemental Fig. 3, available at www.jneurosci.org as supplemental material), it is possible that in vivo PKC-dependent regulation of DAT ubiquitination, internalization, and degradation is more pronounced in the somatodendritic regions of DA neurons located in substantia nigra and ventral tegmental area, rather than in axonal processes. Testing this hypothesis using biochemical methods is in progress in our laboratory. Interestingly, DAT localization in multivesicular bodies, compartments that are responsible for sorting of ubiquitinated cargo, was demonstrated in dendrites and somata of rat DA neurons by electron microscopy (Hersch et al., 1997).

In summary, we propose a working model of DAT endocytosis whereby activation of PKC leads to Nedd4-2 mediated DAT multi-monoubiquitination and/or polyubiquitination. Monoubiquitins and polyubiquitin chains linked through ubiquitin Lys63 are known to serve as trafficking signals (Hicke and Dunn, 2003). Ubiquitinated DAT can interact with adaptor proteins in coated pits, thus promoting DAT internalization. In endosomes, ubiquitinated DAT can interact with ESCRT (endosomal sorting complexes required for transport) proteins containing ubiquitin-
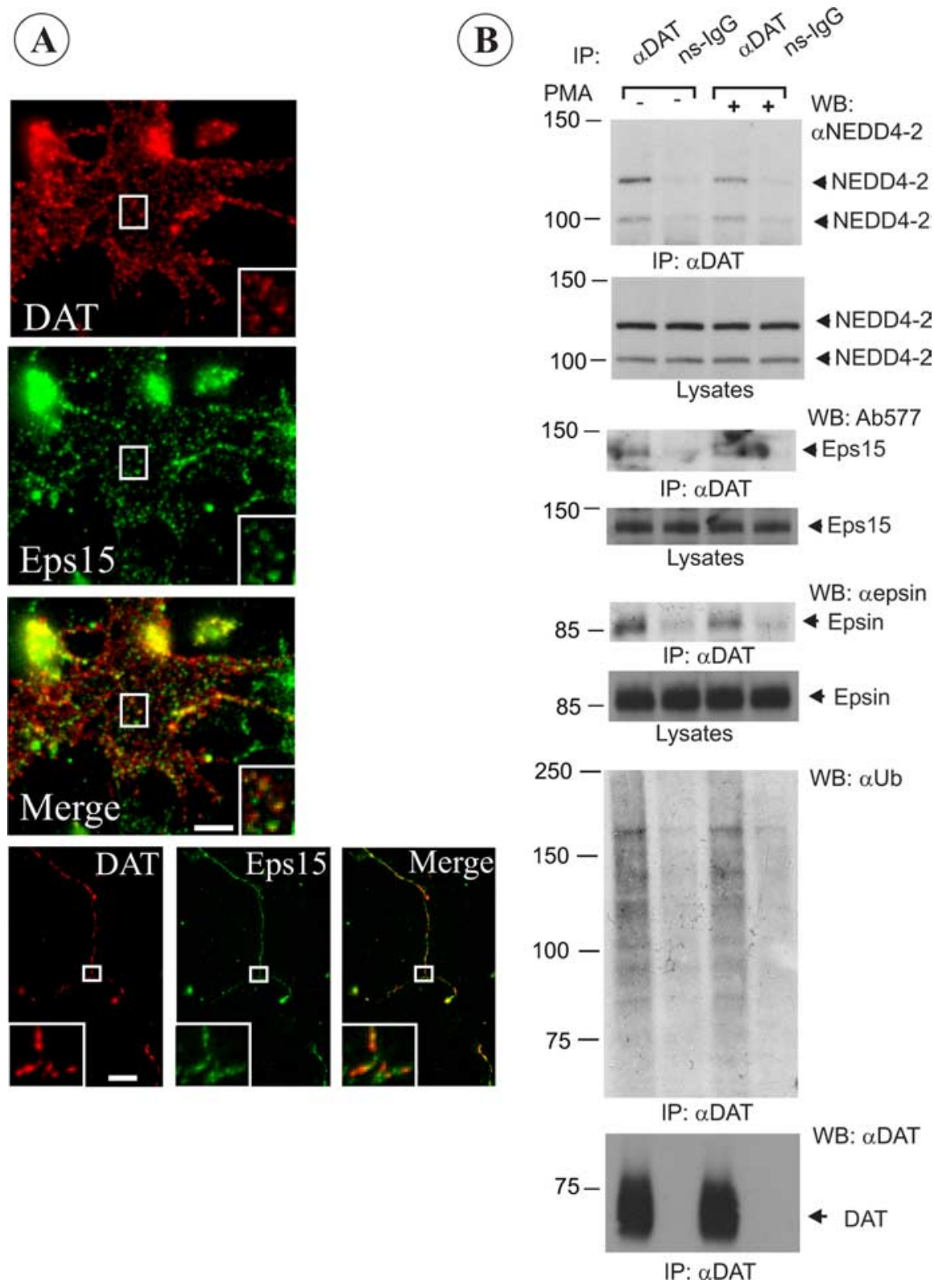

Figure 8. Colocalization of endogenous rat DAT with Eps 15 in coated pits and its interaction with Nedd4 -2, epsin, and Eps 15 . $A$, Mes-Str cultures were fixed and stained with Eps15 and DAT antibodies. High-magnification insets show examples of colocalization of DAT and Eps 15 in punctuate structures (coated pits or vesicles) in an axonal widening and varicosities. Scale bars, $5 \mu \mathrm{m}$. goat anti-DAT antibodies. The immunoprecipitates and aliquots of lysates were resolved by electrophoresis and probed with antibodies to Nedd4 -2, Eps15, and epsin-1, and then antibodies to DAT. Control normal goat lgG (ns-lgG) was used to control for nonspecific immunoprecipitations.

binding domains, become incorporated into intralumenal vesicles of multivesicular bodies, and eventually be degraded by lysosomal enzymes. Thus, knockdown of Nedd4-2 can potentially affect both internalization and postendocytic sorting of DAT. More precise kinetic measurements of endocytic parameters of HA-DAT are required to determine whether ubiquitination plays a role in internalization or lysosomal targeting, or both of these steps of DAT trafficking. That the PKC-dependent internalization step is controlled by DAT ubiquitination is suggested by the involvement of epsin, a protein that is present in coated pit but not in endosomes. Constitutive endocytosis and turnover of DAT may be partially regulated by the same mechanisms, given that a pool of DAT is constitutively ubiquitinated. DAT can be also 
internalized in an ubiquitin-independent manner, for instance, using unconventional signals in the C-terminal tail (Holton et al., 2005). Thus, the hypothesis can be put forward for future testing that the rates of internalization and/or lysosomal targeting of DAT in all types of cells, including neurons, are determined by the extent of DAT ubiquitination and/or the size of the pool of ubiquitinated DATs.

\section{References}

Aguilar RC, Watson HA, Wendland B (2003) The yeast Epsin Ent1 is recruited to membranes through multiple independent interactions. J Biol Chem 278:10737-10743.

Benmerah A, Bayrou M, Cerf-Bensussan N, Dautry-Varsat A (1999) Inhibition of clathrin-coated pit assembly by an Eps15 mutant. J Cell Sci 112:1303-1311.

Boehmer C, Wilhelm V, Palmada M, Wallisch S, Henke G, Brinkmeier H, Cohen P, Pieske B, Lang F (2003a) Serum and glucocorticoid inducible kinases in the regulation of the cardiac sodium channel SCN5A. Cardiovasc Res 57:1079-1084.

Boehmer C, Okur F, Setiawan I, Broer S, Lang F (2003b) Properties and regulation of glutamine transporter SN1 by protein kinases SGK and PKB. Biochem Biophys Res Commun 306:156-162.

Boehmer C, Henke G, Schniepp R, Palmada M, Rothstein JD, Broer S, Lang F (2003c) Regulation of the glutamate transporter EAAT1 by the ubiquitin ligase Nedd $4-2$ and the serum and glucocorticoid-inducible kinase isoforms SGK1/3 and protein kinase B. J Neurochem 86:1181-1188.

Boese Q, Samarsky D, Huang F, Sorkin A (2006) siARRAY reverse transfection format (RTF): a rapid method for RNAi-based high-throughput studies of biological pathways. Nat Methods 1:37-38.

Chen NH, Reith ME, Quick MW (2004) Synaptic uptake and beyond: the sodium- and chloride-dependent neurotransmitter transporter family SLC6. Pflügers Arch 447:519-531.

Chi L, Reith ME (2003) Substrate-induced trafficking of the dopamine transporter in heterologously expressing cells and in rat striatal synaptosomal preparations. J Pharmacol Exp Ther 307:729-736.

Ciliax BJ, Heilman C, Demchyshyn LL, Pristupa ZB, Ince E, Hersch SM, Niznik HB, Levey AI (1995) The dopamine transporter: immunochemical characterization and localization in brain. J Neurosci 15:1714-1723.

Cupers P, ter Haar E, Boll W, Kirchhausen T (1997) Parallel dimers and anti-parallel tetramers formed by epidermal growth factor receptor pathway substrate clone 15 (EPS15). J Biol Chem 272:33430-33434.

Daniels GM, Amara SG (1999) Regulated trafficking of the human dopamine transporter. Clathrin-mediated internalization and lysosomal degradation in response to phorbol esters. J Biol Chem 274:35794-35801.

Debonneville C, Flores SY, Kamynina E, Plant PJ, Tauxe C, Thomas MA, Munster C, Chraibi A, Pratt JH, Horisberger JD, Pearce D, Loffing J, Staub O (2001) Phosphorylation of Nedd4-2 by Sgk1 regulates epithelial $\mathrm{Na}(+)$ channel cell surface expression. EMBO J 20:7052-7059.

Dunnett SB, Bjorklund A (1992) Neural transplantation: a practical approach (Rickwood D, Hames BD, eds). New York: Oxford UP.

Flores SY, Debonneville C, Staub O (2003) The role of Nedd4/Nedd4-like dependant ubiquitylation in epithelial transport processes. Pflügers Arch 446:334-338.

Gulley JM, Zahniser NR (2003) Rapid regulation of dopamine transporter function by substrates, blockers and presynaptic receptor ligands. Eur J Pharmacol 479:139-152.

Hersch SM, Yi H, Heilman CJ, Edwards RH, Levey AI (1997) Subcellular localization and molecular topology of the dopamine transporter in the striatum and substantia nigra. J Comp Neurol 388:211-227.

Hicke L, Dunn R (2003) Regulation of membrane protein transport by ubiquitin and ubiquitin-binding proteins. Annu Rev Cell Dev Biol 19:141-172.

Hicke L, Schubert HL, Hill CP (2005) Ubiquitin-binding domains. Nat Rev Mol Cell Biol 6:610-621.

Holton KL, Loder MK, Melikian HE (2005) Nonclassical, distinct endocytic signals dictate constitutive and PKC-regulated neurotransmitter transporter internalization. Nat Neurosci 8:881-888.

Huang F, Khvorova A, Marshall W, Sorkin A (2004) Analysis of clathrin- mediated endocytosis of epidermal growth factor receptor by RNA interference. J Biol Chem 279:16657-16661.

Itani OA, Campbell JR, Herrero J, Snyder PM, Thomas CP (2003) Alternate promoters and variable splicing lead to hNedd4-2 isoforms with a C2 domain and varying number of WW domains. Am J Physiol Renal Physiol 285:F916-929.

Jiang X, Sorkin A (2003) Epidermal growth factor receptor internalization through clathrin-coated pits requires Cbl RING finger and proline-rich domains but not receptor polyubiquitylation. Traffic 4:529-543.

Kamynina E, Debonneville C, Bens M, Vandewalle A, Staub O (2001) A novel mouse Nedd4 protein suppresses the activity of the epithelial $\mathrm{Na}^{+}$ channel. FASEB J 15:204-214.

Kumar S, Harvey KF, Kinoshita M, Copeland NG, Noda M, Jenkins NA (1997) cDNA cloning, expression analysis, and mapping of the mouse Nedd4 gene. Genomics 40:435-443.

Loder MK, Melikian HE (2003) The dopamine transporter constitutively internalizes and recycles in a protein kinase C-regulated manner in stably transfected PC12 cell lines. J Biol Chem 278:22168-22174.

McMahon HT, Mills IG (2004) COP and clathrin-coated vesicle budding: different pathways, common approaches. Curr Opin Cell Biol 16:379-391.

Melikian HE (2004) Neurotransmitter transporter trafficking: endocytosis, recycling, and regulation. Pharmacol Ther 104:17-27.

Melikian HE, Buckley KM (1999) Membrane trafficking regulates the activity of the human dopamine transporter. J Neurosci 19:7699-7710.

Miranda M, Sorkina T, Grammatopoulos TN, Zawada WM, Sorkin A (2004) Multiple molecular determinants in the carboxyl terminus regulate dopamine transporter export from endoplasmic reticulum. J Biol Chem 279:30760-30770.

Miranda M, Wu CC, Sorkina T, Korstjens DR, Sorkin A (2005) Enhanced ubiquitylation and accelerated degradation of the dopamine transporter mediated by protein kinase C. J Biol Chem 280:35617-35624.

Morgan JR, Prasad K, Jin S, Augustine GJ, Lafer EM (2003) Eps15 homology domain-NPF motif interactions regulate clathrin coat assembly during synaptic vesicle recycling. J Biol Chem 278:33583-33592.

Rougier JS, van Bemmelen MX, Bruce MC, Jespersen T, Gavillet B, Apotheloz F, Cordonier S, Staub O, Rotin D, Abriel H (2005) Molecular determinants of voltage-gated sodium channel regulation by the Nedd4/Nedd4like proteins. Am J Physiol Cell Physiol 288:C692-701.

Saunders C, Ferrer JV, Shi L, Chen J, Merrill G, Lamb ME, Leeb-Lundberg LM, Carvelli L, Javitch JA, Galli A (2000) Amphetamine-induced loss of human dopamine transporter activity: an internalization-dependent and cocaine-sensitive mechanism. Proc Natl Acad Sci USA 97:6850-6855.

Shih SC, Katzmann DJ, Schnell JD, Sutanto M, Emr SD, Hicke L (2002) Epsins and Vps27p/Hrs contain ubiquitin-binding domains that function in receptor endocytosis. Nat Cell Biol 4:389-393.

Sigismund S, Woelk T, Puri C, Maspero E, Tacchetti C, Transidico P, Di Fiore PP, Polo S (2005) From the cover: clathrin-independent endocytosis of ubiquitinated cargos. Proc Natl Acad Sci USA 102:2760-2765.

Snyder PM, Steines JC, Olson DR (2004) Relative contribution of Nedd4 and Nedd $4-2$ to $\mathrm{ENaC}$ regulation in epithelia determined by RNA interference. J Biol Chem 279:5042-5046.

Sorkina T, Doolen S, Galperin E, Zahniser NR, Sorkin A (2003) Oligomerization of dopamine transporters visualized in living cells by fluorescence resonance energy transfer microscopy. J Biol Chem 278:28274-28283.

Sorkina T, Hoover BR, Zahniser NR, Sorkin A (2005) Constitutive and protein kinase $\mathrm{C}$-induced internalization of the dopamine transporter is mediated by a clathrin-dependent mechanism. Traffic 6:157-170.

Thomas CP, Itani OA (2004) New insights into epithelial sodium channel function in the kidney: site of action, regulation by ubiquitin ligases, serum- and glucocorticoid-inducible kinase and proteolysis. Curr Opin Nephrol Hypertens 13:541-548.

Torres GE, Gainetdinov RR, Caron MG (2003) Plasma membrane monoamine transporters: structure, regulation and function. Nat Rev Neurosci 4:13-25.

Yamashita A, Singh SK, Kawate T, Jin Y, Gouaux E (2005) Crystal structure of a bacterial homologue of $\mathrm{Na}(+) / \mathrm{Cl}(-)$-dependent neurotransmitter transporters. Nature 437:215-223.

Zahniser NR, Sorkin A (2004) Rapid regulation of the dopamine transporter: role in stimulant addiction? Neuropharmacology 47 [Suppl 1]:80-91. 